\title{
Assessment of Subclinical Carotid Atherosclerosis in Patients with Chronic Obstructive Pulmonary Disease
}

\author{
T.S.Essawy ${ }^{1}$, A.H.Al-Aarag ${ }^{1}$, I.M.Mustafa ${ }^{2}$, S.S.Ayoub ${ }^{1}$ and E.A.Mohamed ${ }^{1}$ \\ ${ }^{1}$ Chest Diseases, Dept., Faculty of Medicine, Benha Univ., Benha, Egypt. \\ ${ }^{2}$ Radiology, Dept., Faculty of Medicine, Benha Univ., Benha, Egypt. \\ E-Mail: Samarsamy828@gmail.com
}

\begin{abstract}
Background: Elevated coronary morbidity and mortality of patients with chronic obstructive pulmonary diseases (COPD). Common intimate-media thickening (CCA-IMT) and carotid plaques are replacement markers of atherosclerosis and predictors of $\mathrm{CV}$ cases. Purpose and objectives: The present research aimed at assessing and evaluating the incidence of subclinical carotid atherosclerotic vascular diseases in patients with COPD Sujets and methods: a cross-sectional sample of 75 topics has been conducted; 25 stable COPD patients and 50 controls (25 patients with other chest diseases and 25 apparently healthy persons). They were divided into three groups: Group I: 25 healthy COPD patients (Global initiative for Chronic Obstructive Lung Disease Recommendations 2020 diagnosis and gravity of COPD) (GOLD 2020). Group II: 25 people and other underlying pulmonary conditions. Group III: 25 people seemingly well. The thesis lasted between 6 and 12 months Results: The prevalence of carotid disease in COPD patients was slightly higher than controls. Multinomial analyses of logistic regression have shown COPD to be an independent carotid plague indicator. Conclusion: Subclinical atherosclerosis is greatly correlated with COPD. These results will help to prepare appropriate strategies for CV prevention.
\end{abstract}

Keywords: chronic obstructive pulmonary disease, subclinical atherosclerosis, intima-media thickness, and carotid plaques.

\section{Introduction}

Chronic Obstructive Pulmonary Disease (COPD) is an abnormal disease widespread and preventive and treatable, with chronic respiratory symptoms and airflow limitations, commonly exacerbated by substantial exposures to noxious particles or gases, attributable to airways or alveolar defects. It is a significant cause of global morbidity and death. It is the world's fourth largest cause of death and is expected to become the third largest cause of death by 2020 [1]. Different comorbidities are correlated with COPD. Cardiovascular disorders, cancer, cachexia, osteoporosis, depression and anaemia are the frequently identified comorbidities of COPD [2]. Cardiovascular diseases stated to be more common in COPD patients than in the general population include atherosclerosis, $\mathrm{CAD}$, congestive heart failure (CHF), peripheral vascular disease (PVD) and cardiac arrhythmia [3]. The key to connecting COPD to cardiovascular disease is low-grade systemical inflammation [4]. The leading cause of coronary heart attack, stroke and peripheral vascular disease (PVD) is atherosclerosis [5]. The intima media thickness of carotids (CIMT) is an indicator of preclinical carotid atherosclerosis, which can be used to diagnose atherosclerosis and cardiovascular disease risk assessment [6].

Increased CIMT in patients with COPD is correlated with increased overall and cardiovascular mortality, indicating that CIMT assessment is a reliable biomarker of morbidity and death in these patients [7].

\section{Aim of the work}

This study aimed to assess the risk of subclinical carotid atherosclerotic vascular disease in patients with COPD and its relation to disease severity.

\section{Subjects and Methods}

This study was done at Benha university hospital, chest department, included 75 subjects: 25 stable COPD patients and 50 controls (25 patients with chest diseases other than COPD, in period 2019 - 2020 and 25 apparently healthy persons).

They had been classified into 3 groups:

Group I: 25 stable COPD patients (Diagnosis and severity of COPD according to the Global Initiative for Chronic Obstructive Lung Disease guidelines 2020.

Diagnosis of COPD was based on symptoms, physical examination, and presence of risk factors. Diagnosis was confirmed by post-bronchodilator spirometry that was performed $15 \mathrm{~min}$ after administration of four doses of salbutamol sulfate (100 $\mu \mathrm{g})$. Pre-and post-bronchodilator spirometry was performed according to American Thoracic Society/European Respiratory Society recommendations using a spirometer (Spirolab 11) in all subjects [1)]. diseases

Group II : 25 patients with other chronic lung

Group III: 25 apparently healthy persons.

Exclusion criteria

- Patients with coronary artery disease (CAD).

- Patients with hyperlipidemia.

- Patients with COPD exacerbation.

All subjects were subjected to the following:

1. Through history to record demographics, behavioral characteristics and self-reported history of diabetes and hypertension. Exposure to tobacco smoke and biomass-fuel smoke and its intensity and duration were recorded.

2. Complete physical examination (General\& Local).

Physical examination included recording of blood pressure (BP), waist circumference, weight and height. 
Local examination of respiratory system was carried out to document obstructive airway disease and to rule out other forms of pulmonary diseases.

1. Pulmonary function tests by spirometry before and after bronchodilators.

2. Lipid profile (cholesterol, LDL, HDL, TG).

3. Carotid duplex ultrasonography: assessment of carotid wall intima media thickness (IMT

- Plain chest X-ray (P.A view, lateral view).

- Arterial blood gases analysis.

- Laboratory investigation (e.g. KFTs ,LFTs ,CBC)

- ECG

\section{Data management and Statistical Analysis:}

Collected data were recorded then presented and analyzed statistically by computer using SPSS version 22(SPSS Inc. Chicago, IL, U.S.A) as follow:

1. Editing and coding

2. Data entry in computer.

\section{Results}

Table (1) Demographic data of the three studied groups.
3. Data were summarized and presented in tables and graphs and summarized as median and mean \pm standard deviation for quantitative variables and as number and percentage for qualitative variables.

4. Data were handled using appropriate statistical tests of significance such as:

- Shapiro-Wilk's W-test was applied for checking the normality assumption of continuous variables.

- Chi-square test and Fisher's exact test, wherever appropriate, were used for data analysis.

- Independent two-sample $\mathrm{t}$-tests or Mann-Whitney$\mathrm{U}$ tests were applied to compare the continuous variables between the two groups.

- Binary logistic regression models were used to examine the associations between occurrence of acne vulgaris and other parameters.

- P value equal to or less than 0.05 was considered statistically significant

- P value more than 0.05 was considered not significant

\begin{tabular}{|c|c|c|c|c|c|c|c|c|}
\hline & & Group I & $(\mathrm{N}=25)$ & Group II & $(\mathrm{N}=25)$ & Group III & $\mathbf{F} / \chi^{2}$ & $\mathbf{P}$ \\
\hline $\begin{array}{l}\text { Age (years) } \\
\text { Mean } \pm \text { SD }\end{array}$ & & $63.6 \pm 6.65$ & & $63.28 \pm 6.87$ & & $62.28 \pm 6.39$ & 0.27 & 0.765 \\
\hline Sex & $\begin{array}{l}\text { Male } \\
\text { Female }\end{array}$ & $\begin{array}{l}18(72 \%) \\
7(28 \%)\end{array}$ & & $\begin{array}{l}16(64 \%) \\
9(36 \%)\end{array}$ & & $\begin{array}{l}16(64 \%) \\
9(36 \%)\end{array}$ & .480 & 0.787 \\
\hline $\begin{array}{l}\text { Weight (kg) } \\
\text { Mean } \pm \text { SD }\end{array}$ & & $76.48 \pm 5.77$ & & $78.88 \pm 5.36$ & & $78.2 \pm 5.28$ & 1.28 & 0.285 \\
\hline $\begin{array}{l}\text { Height }(\mathrm{cm}) \\
\text { Mean } \pm \text { SD }\end{array}$ & & $168.1 \pm 6.16$ & & $165.68 \pm 6.85$ & & $164.28 \pm 6.64$ & 2.15 & 0.124 \\
\hline $\begin{array}{l}\mathrm{BMI}\left(\mathrm{kg} / \mathrm{m}^{2}\right) \\
\operatorname{Mean} \pm \mathrm{SD}\end{array}$ & & $28.59 \pm 3.44$ & & $28.87 \pm 3.03$ & & $28.8 \pm 2.68$ & 0.05 & 0.948 \\
\hline
\end{tabular}

This table shows there is no significant difference between the three studied groups regarding Demographic data.

Table (2) Smoking between the three studied groups.

\begin{tabular}{|c|c|c|c|c|c|c|c|c|}
\hline & Group I & $(\mathrm{N}=25)$ & Group II & $(\mathrm{N}=25)$ & Group III & $(\mathrm{N}=25)$ & \multirow{2}{*}{$\chi^{2}$} & \multirow[b]{2}{*}{$\mathbf{P}$} \\
\hline & $\mathbf{N}$ & $\%$ & $\mathbf{N}$ & $\%$ & $\mathbf{N}$ & $\%$ & & \\
\hline \multicolumn{9}{|l|}{ Smoking } \\
\hline Current smoker & 17 & 68 & 14 & 56 & 0 & 0 & \multirow{4}{*}{58.36} & \multirow{4}{*}{$<0.001 *$} \\
\hline Ex-smoker & 8 & 32 & 6 & 24 & 0 & 0 & & \\
\hline Non-smoker & 0 & 0 & 5 & 20 & 25 & 100 & & \\
\hline $\begin{array}{l}\text { Smoking amount, } \\
\text { pack-years }\end{array}$ & $23.1 \pm 14.5$ & & $21.9 \pm 17.1$ & & ---- & & & \\
\hline
\end{tabular}

This table shows There is significant difference between the three studied groups regarding Smoking status, Current smoker Ex-smoker Non-smoker Smoking amount, pack-years.

Table (3) Pulmonary function tests between the three studied groups.

\begin{tabular}{|c|c|c|c|c|c|c|}
\hline & Group I $(\mathbf{N}=25)$ & Group II & Group III $\quad(\mathrm{N}=25)$ & $\mathbf{F}$ & $\mathbf{P}$ & LSD \\
\hline $\begin{array}{l}\text { FVC }(\%) \\
\text { Mean } \pm \text { SD }\end{array}$ & $59.24 \pm 11.4$ & $66.56 \pm 10.74$ & $81.76 \pm 6.85$ & 33.9 & $<0.001 *$ & $\begin{array}{l}P_{1}=0.011^{*} \\
P_{2}<0.001 \\
P_{3}=.000\end{array}$ \\
\hline $\begin{array}{l}\text { FEV1 }(\%) \\
\text { Mean } \pm \text { SD }\end{array}$ & $41.52 \pm 11.28$ & $45.24 \pm 15.14$ & $70.28 \pm 9.40$ & 41.3 & $<0.001 *$ & $\begin{array}{l}\mathrm{P}_{1}=0.284 \\
\mathbf{P}_{\mathbf{2}}<\mathbf{0 . 0 0 1} *\end{array}$ \\
\hline
\end{tabular}




\begin{tabular}{|c|c|c|c|c|c|c|}
\hline & & & & & & $\mathrm{P}_{3}<0.001 *$ \\
\hline $\begin{array}{l}\text { FEV1/FVC }(\%) \\
\text { Mean } \pm \text { SD }\end{array}$ & $70.72 \pm 15.38$ & $69.53 \pm 23.66$ & $86.36 \pm 13.36$ & 6.8 & $0.002 *$ & $\begin{array}{l}\mathrm{P}_{1}=0.817 \\
\mathbf{P}_{\mathbf{2}}=\mathbf{0 . 0 0 3} * \\
\mathbf{P}_{\mathbf{3}}=\mathbf{0 . 0 0 2} *\end{array}$ \\
\hline
\end{tabular}

FVC: Forced vital capacity, FEV: Forced expiratory volume

This table shows There is a significant difference between the three studied groups regarding pulmonary function tests.

Table (4) Lipid profile between the three studied groups.

\begin{tabular}{|c|c|c|c|c|c|c|}
\hline & Group I & Group II $\quad(\mathrm{N}=25)$ & Group III $(\mathrm{N}=25)$ & $\mathbf{F}$ & $\mathbf{P}$ & LSD \\
\hline $\begin{array}{l}\text { TC }(\mathrm{mg} / \mathrm{dl}) \\
\text { Mean } \pm \mathrm{SD}\end{array}$ & $181.08 \pm 48.04$ & $193.04 \pm 46.48$ & $171.84 \pm 25.17$ & 1.661 & 0.197 & $\begin{array}{l}\mathrm{P}_{1}=0.309 \\
\mathrm{P}_{2}=0.431 \\
\mathrm{P}_{3}=0.073\end{array}$ \\
\hline $\begin{array}{l}\text { TG }(\mathrm{mg} / \mathrm{dl}) \\
\text { Mean } \pm \mathrm{SD}\end{array}$ & $142.4 \pm 60.89$ & $155.32 \pm 44.3$ & $141.2 \pm 10.40$ & 0.798 & 0.454 & $\begin{array}{l}\mathrm{P}_{1}=0.302 \\
\mathrm{P}_{2}=0.921 \\
\mathrm{P}_{3}=0.258\end{array}$ \\
\hline $\begin{array}{l}\text { LDL }(\mathrm{mg} / \mathrm{dl}) \\
\text { Mean } \pm \text { SD }\end{array}$ & $162.44 \pm 52.39$ & $174.92 \pm 44.83$ & $87.20 \pm 10.32$ & 34.739 & $<0.001 *$ & $\begin{array}{l}\mathrm{P}_{1}=0.277 \\
\mathrm{P}_{2}<0.001 * \\
\mathrm{P}_{3}<0.001 *\end{array}$ \\
\hline $\begin{array}{l}\text { HDL } \\
(\mathrm{mg} / \mathrm{dl}) \\
\text { Mean } \pm \mathrm{SD}\end{array}$ & $61.08 \pm 20.43$ & $53.08 \pm 20.76$ & $127.08 \pm 7.25$ & 137.295 & $<0.001 *$ & $\begin{array}{l}\mathrm{P}_{1}=0.107 \\
\mathrm{P}_{2}<0.001 * \\
\mathrm{P}_{3}<0.001 *\end{array}$ \\
\hline
\end{tabular}

TG: triglycerides, LDL: low density lipid, HDL: high density lipid

This table shows There is significant difference between the three studied groups regarding LDL and HDL.

Table (5) Intima media thickness between the three studied groups.

\begin{tabular}{|c|c|c|c|c|c|c|}
\hline & Group I & Group II $\quad(\mathrm{N}=25)$ & Group III $\quad(\mathrm{N}=25)$ & $\mathbf{F}$ & $\mathbf{P}$ & LSD \\
\hline $\begin{array}{l}\text { IMT }(\mathbf{m m}) \\
\text { Mean } \pm \text { SD }\end{array}$ & $\begin{array}{l}0.89 \pm 0.282 \\
0.6-1.5\end{array}$ & $\begin{array}{l}0.684 \pm 0.137 \\
0.4-1\end{array}$ & $\begin{array}{l}0.62 \pm 0.073 \\
0.48-0.70\end{array}$ & 14.102 & $<0.001 *$ & $\begin{array}{l}\mathbf{P}_{\mathbf{1}}<0.001 * \\
\mathbf{P}_{\mathbf{2}}<0.001 * \\
\mathrm{P}_{3}=0.233\end{array}$ \\
\hline
\end{tabular}

This table shows There is a significant difference between the three studied groups regarding intima media thickness. Otherwise, there was a significant difference was found between group I and each of group II and group III regarding IMT.

Table (6) Correlation of Intima media thickness with demographic data.

\begin{tabular}{lcccccc}
\hline & Group I & $\mathbf{N}=\mathbf{2 5})$ & Group II & \multicolumn{1}{c}{$\mathbf{( N = 2 5 )}$} & Group III & \multicolumn{1}{c}{$\mathbf{( N = 2 5 )}$} \\
\cline { 2 - 7 } & $\mathbf{r}$ & $\mathbf{p}$ & $\mathbf{r}$ & $\mathbf{P}$ & $\mathbf{r}$ & $\mathbf{P}$ \\
\hline Age & 0.095 & 0.653 & -0.221 & 0.289 & -0.009 & 0.966 \\
BMI & 0.029 & 0.892 & 0.024 & 0.909 & 0.069 & 0.741 \\
\hline
\end{tabular}

This table shows there is no significant correlation between Intima media thickness with demographic data.

Table (7) Correlation of Intima media thickness with pulmonary function.

\begin{tabular}{lcccccc}
\hline & Group I & $\mathbf{( N = 2 5 )}$ & Group II & \multicolumn{1}{c}{$(\mathbf{N}=25)$} & Group III & $(\mathbf{N}=25)$ \\
\cline { 2 - 7 } & $\mathbf{r}$ & $\mathbf{p}$ & $\mathbf{r}$ & $\mathbf{P}$ & $\mathbf{r}$ & $\mathbf{P}$ \\
\hline FVC \% & -0.178 & 0.395 & -0.163 & 0.436 & -0.084 & 0.689 \\
FEV1 \% & 0.052 & 0.806 & 0.122 & 0.561 & 0.138 & 0.510 \\
FEV1/FVC & 0.247 & 0.235 & 0.227 & 0.276 & 0.166 & 0.428 \\
\hline
\end{tabular}

This table shows there is no significant correlation between Intima media thickness with pulmonary function. 
Table (8) Correlation of Intima media thickness with lipid profile.

\begin{tabular}{lcccccc}
\hline & Group I & $\mathbf{( N = 2 5 )}$ & Group II & \multicolumn{1}{c}{$\mathbf{( N = 2 5 )}$} & Group III & $\mathbf{( N = 2 5 )}$ \\
\cline { 2 - 7 } & $\mathbf{r}$ & $\mathbf{p}$ & $\mathbf{r}$ & $\mathbf{p}$ & $\mathbf{r}$ & $\mathbf{P}$ \\
\hline TC & -0.059 & 0.779 & 0.301 & 0.144 & 0.014 & 0.946 \\
HDL & 0.363 & 0.075 & 0.148 & 0.480 & -0.280 & 0.176 \\
LDL & 0.406 & $0.044 *$ & -0.108 & 0.606 & -0.021 & 0.922 \\
TG & 0.111 & 0.599 & 0.004 & 0.986 & -0.062 & 0.768 \\
\hline
\end{tabular}

This table shows there is a significant positive correlation between IMT and LDL in group I.

Table (9) Correlation of Intima media thickness with smoking.

\begin{tabular}{|c|c|c|c|c|c|c|}
\hline & Group I & $(\mathrm{N}=25)$ & Group II & $(\mathrm{N}=25)$ & Group III & $(\mathrm{N}=25)$ \\
\hline & $\mathbf{r}$ & $\mathbf{p}$ & $\mathbf{r}$ & $\mathbf{p}$ & $\mathbf{r}$ & $\mathbf{P}$ \\
\hline Smoking & -0.309 & 0.132 & 0.016 & 0.938 & ---- & ---- \\
\hline
\end{tabular}

This table shows there is no significant correlation between Intima media thickness with smoking.

\section{Discussion}

Chronic pulmonary obstruction (COPD) disorder is a chronic, gradual pulmonary condition and a growing source of global morbidity and mortality. In comparison to the pattern for cardiovascular disease (CV), in the last decade the mortality rate for COPD has gradually increased, which, according to predictions by the World Health Organization (WHO), may become the third leading worldwide cause of death by 2030 [8].

In recent years, there has been an increasing understanding of the structural complexities of COPD and the repeated and severe chronic comorbidities that may make a significant contribution to its incidence and mortality. Numerous examinations, cross-sectional and longitudinal trials, in fact, have shown that in COPD patients, $\mathrm{CV}$ disease is more common than in the general population, posing a burden far greater than lung disease itself in this clinical environment [9].

It is predicted that $\mathrm{CV}$ mortality is almost 30 percent higher per 10 percent decline in lung capacity [as expressed by forced expiratory volume in one second (FEV1)]. COPD and CV disorder share several important risk factors, such as smoking, diabetes mellitus, high blood pressure and obesity [10].

However, some literature confirms that COPD is consistent with $\mathrm{CV}$ manifestations irrespective of concurrent risk factors, which suggests that COPD itself should be regarded as a separate $\mathrm{CV}$ risk factor. To counter this concern further care has been taken to evaluate the relationship between COPD and a known predictor of $\mathrm{CV}$ disorder, subclinical atherosclerosis [11].

Carotid intima-media (IMT) thickness measurement has been generally acknowledged as one of the best predictors in significant $\mathrm{CV}$ cases as a not intrusive imaging procedure for subclinical atherosclerosis (stroke, myocardial infarction, heart failure, or CV death). Carotid plaques are used as a far more accurate indicator of CV incidents than IMT. These substitute markers of subclinical atherosclerosis therefore provide valuable prognostic details on more than typical risk factors for CV [12].

Prospective and retrospective trials of COPD patients have reported accelerated atherosclerosis. The evidence is therefore constrained by small samples and possible mitigating variables, and no meta-analytical data are accessible currently offering clarity on this topic [13].

The aim of this research was to evaluate the likelihood of subclinical carotid atherosclerotic disease and its relationship to disease intensity in patients with COPD.

A cross-sectional analysis of 75 subjects was conducted: 25 stable COPD patients and 50 controls (25 patients with other chest diseases and 25 apparently healthy persons). They were divided into three groups: Group I: 25 healthy COPD patients (Global initiative for Chronic Obstructive Lung Disease Recommendations 2020 diagnosis and gravity of COPD) (GOLD 2020). Group II: 25 chronic lung disease patients The thesis lasted from 6-12 months.

The major findings of this review were as follows

There was no substantial variation between the three groups tested except with respect to age and BMI.

The findings were in accordance with the kim (14) analysis, which showed no major age, sex \& BMI variations between the COPD groups and non-COPD.

A major source of worldwide morbidity and mortality was chronic obstructive pulmonary disease (COPD). It is mostly a pulmonary condition, with a partly reversible and gradual restriction of airflow. Recent data indicate that COPD is linked to significant structural events. In mild to moderate COPD, coronary problems and cancer are more common, with weight loss and peripheral muscle disease prevalent in serious conditions such as osteoporosis [15].

Different co-morbidities are correlated with COPD. The Global Chronic Obstructive Lung Disease Initiative (GOLD) has stressed the relevance of comorbidities in COPD patients. Cardiovascular disorders, cancer, cachexia, osteoporosis, depression and anaemia 
are the most frequently identified co-morbidities of COPD. Most COPD patients do not die from the lung disease but rather from the corresponding co-morbid ities [2].

The present research found that there was a substantial gap in smoking status between the three studied types. Former cigarette Non-smoking Smoking amount, pack years. Smoking volume.

Contrary to our findings, Chindhi research [16] has shown that there are no substantial variations in COPD and smoking regulation.

The presence of smoking habits was 17.4 percent to -73.6 percent, 25.9 percent to -62.8 percent [17].

Cumulative research has shown that COPD is a pulmonary condition that is often marked by extrapulmonary symptoms and co-morbidities. Cardiovascular disorders are the most common comorbid conditions impacting COPD patients and make a significant contribution to the incidence and prognosis of COPD [18].

Reduced FEV1 itself is a cardiovascular mortality risk factor in COPD patients, regardless of traditional risk factors. Every $10 \%$ FEV1 reduction raises overall mortality by $14 \%$, cardiovascular mortality by $28 \%$ and nonfatal coronary incident by nearly $20 \%$ after changes to age, sex, smoking status and treatment for the related confounders [5].

In our sample, there is an important variation in the pulmonary function measures between the three tested types.

Our analysis of Gulbas [19] endorsed our data by showing important variations in the baseline characteristics of groups such as era, smoking load (pack-years), forced vital ability (FVC) (percent), FEV1 (percent), FEV1/FVC and hypertension (years) variables $(\mathrm{P}<0,05)$. There were $200 \mathrm{CIMT}<0.78 \mathrm{~mm}$ (group 1) and 410 CIMT $<0.78 \mathrm{~mm}$ (group 1) (group 2).

In addition, it is shown that there was a large variation in FEV1 percent in their study classes [20].

The new research found a large variation in LDL and HDL among the three classes tested.

We found that TC, HDL cholesterol, triglycerides, plasma-glucose rapidity, and creatinine were not statistically important variations between the two groups as compared to the Albu [20] research.

The main source of cardiovascular disorder is atherosclerosis. The intima-media thickness (IMT) characterises preclinical carotid atherosclerosis on ultrasound imaging. It provides a replacement marker for atherosclerosis pressure and cardiovascular disease risk evaluation. Low-grade systemic inflammation is considered essential for initiation and development of atherosclerotic diseases in atherosclerosis pathogenesis [21].

In many chronic conditions with prevalent cardiovascular disorders, the connection between systemic inflammatory markers, like CRP, and preclinical carotid atherosclerosis has been recorded. While a lung function is correlated with carotid atherosclerosis, there are few research investigating the association between systemic inflammatory markers and preclinical carotid atherosclerosis in patients with COPD and significant diagnostic flaws in the airflow restriction and subjects [22].

Our analysis found that there were major differences in the intima media thickness between the three groups surveyed. Otherwise, a large difference in IMT between group I and both group II and group III was observed.

There was no meaningful association between the thickness of Intima media and demographic evidence. There was no clear connection between the thickness of the Intima media and lung function. The relationship between IMT and LDL in group 1 was significantly positive. There was no clear connection between the thickness of Intima media and smoking.

In accordance with the study 21, our findings showed that in COPD patients Carotide IMT was substantially superior to in the control group $(1,07 \pm$ $0,25 \mathrm{~mm}$ and $0,86 \pm 0,18 \mathrm{~mm}, \mathrm{p}<0,001)$.

In addition, the COPD group's IMT was shown to be significantly higher than in the non-COPD group ( $P$ $<0,05)$. The decrease in the expiratory volume in 1 second/forced vital power ratio (FEV1/FVC) and in FEV1 was associated significantly with a rise in IMT (P $<0.05)$ (14) [4].

It has been shown that an elevated incidence of cardiovascular disease, as shown by carotid IMT values higher or equivalent to 75th percentile in 14 (28.6 percent), where IMT Hypertrophy was present in 24 (49.0 percent) of patients (IMT values higher and equal to $0.80 \mathrm{~mm}$ ). The mean IMT was $0.85+/-0.21 \mathrm{~mm}$ in the whole cohort with no major deviations from stage II to stage III to stage IV COPD. [23] Carotid plaque (38.7\% vs. $13.7 \%, \mathrm{P}<0.0001)$ and rise in CIMT in patients with COPD (67.6\% vs. $25.8 \%)$ is substantially higher relative to age and sex-matched controls [16].

The mean carotid wall IMT in the sample by van Gestel [7] was $1.07 \mathrm{~mm}$. 23\% of patients without COPD showed increased CIMT, while $32 \%$ of patients with mild COPD and $36 \%$ of patients with moderate/severe COPD had increased CIMT $(\mathrm{P}<0,01)$. COPD was also identified as an autonomous risk factor for increased CIMT. Iwamoto [24] recorded a higher mean CIMT among male smokers with an obstruction to the airflow than control smokers and never smokers, meaning that an atherosclerosis is correlated with airflow restriction rather than smoking individual. CIMT is an effective indicator of predicted cardiovascular risk and is a more effective predictor of cardiovascular problems relative to the conventional risk factors.

Carotid intima-media thickness and carotid plaques were considerably higher as compared to COPD patients the ankle brachial index was substantially smaller.

\section{Conclusions}

COPD was significantly associated with subclinical atherosclerosis, and, in turn, with an increased CV risk. Thus, patients with COPD may 
benefit from a more meticulous screening for $\mathrm{CV}$ risk factors and more specific CV prevention strategies, even in an early stage of the lung disease.

\section{References}

[1] Global Initiative for Chronic Obstructive Lung Disease ,Global strategy for the diagnosis, management and prevention of chronic obstructive pulmonary disease. NHLBI/WHO Global Initiative for Chronic Obstructive Lung Disease (GOLD), 2020.

[2] A.R Patel, J.R.Hurst, Extra pulmonary comorbidities in chronic Obstructive pulmonary disease: State of the art. Expert Rev Respir Med ;vol. 5,pp.647-62,2011.

[3] S.Aryal, , E.Diaz Guzman, , D.M. Mannino, Epidemiology of comorbidities in chronic obstructive pulmonary disease: Clusters, phenotypes andoutcomes. Italian Journal of Medicine;vol. 6,pp.276-84,2012.

[4] L.M.Fabbri, F.Luppi , B.Beghé, K.F. Rabe, Complex chronic comorbiditiesof COPD. EurRespir J;vol.31,pp.204-12,2018.

[5] D.P.Faxon, V.Fuster, P.Libby, J.A.Beckman, W.R.Hiatt, R.W.Thompson, American Heart Association. Atherosclerotic vascular disease conference: Writing Group III: Pathophysiology. Circulation;vol.109,pp.2617-25,2004.

[6] E.B.Schroeder, V.L.Welch, G.W.Evans, G. Heiss, Impaired lung function and subclinical atherosclerosis. The ARIC study. Atherosclerosis ;vol. 180,pp.367-73,2005.

[7] Y.R.van Gestel, W.J.Flu, J.P.van Kuijk, S.E.Hoeks, J.J.Bax, D.D.Sin, Association of COPD with carotid wall intima-media thickness in vascular surgery patients. Respir Med. 2010 May;vol. 104(5),pp.712-716,2010.

[8] H.Sharma, P.Kapur, R. K.Jalali, K.Dubey, Atherosclerosis risk assessment in patients with chronic obstructive pulmonary disease: a casecontrol study. Therapeutics and clinical risk management;vol. 15,pp.10-61,2019.

[9] G.Hillas, F.Perlikos, I.Tsiligianni, N.Tzanakis, Managing comorbidities in COPD. Int J Chron Obstruct Pulmon Dis;vol.10,pp.95-109,2015.

[10] N.Cebron Lipovec, R.J.Beijers , B.van den Borst, W.Doehner, M.Lainscak, A.M. Schols, The Prevalence of Metabolic Syndrome In Chronic Obstructive Pulmonary Disease: A Systematic Review. COPD;vol.13,pp.399-406,2016.

[11] I.S.Stone, N.C.Barnes, S.E.Petersen, Chronic obstructive pulmonary disease: a modifiable risk factor for cardiovascular disease? Heart;vol. 98,pp.1055-62,2012.

[12] G.Belcaro, A.N.Nicolaides, G.Ramaswami, M.R.Cesarone, M.De Sanctis, L.Incandela, Carotid and femoral ultrasound morphology screening and cardiovascular events in low risk subjects: a 10-year follow-up study (the CAFES-
CAVE study. Atherosclerosis;vol.156,pp.379$87,2011$.

[13] R.W.Joshi, R.Agrawal, M.S.Pandharipande, P.P. Joshi, Carotid intima media thickness in chronic obstructive pulmonary disease. VJIM.;vol.20,pp.19-23,2016.

[14] S. J.Kim, D. W.Yoon, E. J.Lee, G. Y.Hur, K. H.Jung, S. Y.Lee, Carotid atherosclerosis in patients with untreated chronic obstructive pulmonary disease. The International journal of tuberculosis and lung disease;vol. 15(9),pp. 1265$1270,2011$.

[15] R.Broekhuizen, E.F.Wouters, E.C.Creutzberg, A. M. Schols, Raised CRP levels mark metabolic and functional impairement in advanced COPD. Thorax ;vol.61,pp. 17-22,2006.

[16] S.Chindhi, S.Thakur, M.Sarkar, P. C. Negi, Subclinical atherosclerotic vascular disease in chronic obstructive pulmonary disease: Prospective hospital-based case control study. Lung India: Official Organ of Indian Chest Society;vol. 32(2),pp.130- 137,2015.

[17] P.Ambrosino, R.Lupoli, G.Cafaro, S.Iervolino, , M.Carone, N.Pappone, Subclinical carotid atherosclerosis in patients with chronic obstructive pulmonary disease: a meta-analysis of literature studies. Annals of Medicine;vol. 49(6), pp.513$524,2017$.

[18] J.Vestbo, S.S.Hurd, A.G.Agusti, P.W.Jones, C.Vogelmeier, A.Anzueto, Global strategy for the diagnosis, management, and prevention of chronic obstructive pulmonary disease: GOLD executive summary Am. J. Respir. Crit. Care. Med;vol. 187, pp. 347-365,2013.

[19] G.Gulbas, O.Turan, N.Sarioglu, O. E.Diken, N.Ogan, E.Ekbic Kadioglu, Carotid intima-media thickness in chronic obstructive pulmonary disease and survival: A multicenter prospective study. The clinical respiratory journal;vol. 13(6),pp 391$399,2019$.

[20]A.Albu, D.Fodor, C.Bondor, O. Suciu, Carotid arterial stiffness in patients with chronic obstructive pulmonary disease. Acta physiologica Hungarica;vol. 98(2),pp. 117-127,2011.

[21] a.O.Alpaydin, I. K.Arslan, S.Serter, A. S.Coskun, P.Celik, F.Taneli, Metabolic syndrome and carotid intima-media thickness in chronic obstructive pulmonary disease. Multidisciplinary respiratory medicine;vol. 8(1),pp, 61-62,2013.

[22]L.Lahousse, Q. J.van den Bouwhuijsen, D. W.Loth, G. F.Joos, A.Hofman, J. C.Witteman, Chronic obstructive pulmonary disease and lipid core carotid artery plaques in the elderly: the Rotterdam Study. American journal of respiratory and critical care medicine;vol. 187(1),pp. 5864,2013.

[23] P.Pobeha, P.Skyba, P.Joppa, Z.Kluchova, E.Szaboova, I.Tkac, Carotid intima-media thickness in patients with chronic obstructive 
pulmonary disease. Bratislavske lekarske listy; vol. 112(1), pp.20-24,2011.

[24] H.Iwamoto, A.Yokoyama, Y.Kitahara, N.Ishikawa, Y.Haruta, K.Yamane, Airflow limitation in smokers is associated with subclinical atherosclerosis. Am J Respir Crit Care Med. 2009 Jan 1; vol.179(1),pp.35-40,2009.

[25] S. H.Sadek, A. A.Hassan, G.AbdElrahman, S. M.Kasem, L.AbdElwahed, S.H.Eldein, Subclinical cardiovascular changes in chronic obstructive pulmonary disease patients: Doppler ultrasound evaluation. Egyptian Journal of Bronchology; vol. 9(2), pp.142-140,2015. 